\title{
Prune belly syndrome
}

INSERM

\section{Source}

INSERM. (1999). Orphanet: an online rare disease and orphan drug data base. Prune belly syndrome. ORPHA:2970

Prune belly syndrome is a rare congenital disorder, belonging to the group of fetal lower urinary tract obstructions (LUTO), involving variable dilation of the lower urinary tract in association with partial or complete absence of the lateral and inferior abdominal wall musculature and in males bilateral non-palpable undescended testes. 